Archived version from NCDOCKS Institutional Repository http://libres.uncg.edu/ir/asu/

\title{
Appalach $\operatorname{lyan}_{S T A T E}$
}

$\bar{B}$ O O N E, N O R T H A R O L N A

\section{Formulating Strategic Direction For A Gated Residential Community}

\author{
By: Richard W. Pouder and J. Dana Clark
}

\begin{abstract}
Over the past two decades, a growing number of Americans have decided to live in gated residential communities. Academic research and case studies tend to focus on explaining this growth phenomenon from a range of perspectives, yet surprisingly little has been written about the preservation and growth of existing gated communities. In response to this gap in the literature, the purpose of this paper is to illustrate the use of strategic planning as a means of addressing issues that pertain to sustaining and growing gated residential communities. This paper applies principles of strategic management to the process of planning for residential preservation and growth. The residential context is a golf-focused gated community located in the mountains of western North Carolina. It uses focus groups as a qualitative means of identifying important strategic issues. These issues serve as the basis for designing a survey for community residents. The survey results provide quantitative information that enables development of strategies targeted toward preservation and growth of the community. Results from this paper suggest that traditional strategic planning techniques provide an effective method that common interest housing developments can use to help identify and respond to issues affecting their viability and growth.
\end{abstract}

Richard W. Pouder, J. Dana Clark, (2009) "Formulating strategic direction for a gated residential community", Property Management, Vol. 27 Issue: 4, pp.216-227, https://doi.org/10.1108/02637470910979989. Publisher version of record available at: https://www.emeraldinsight.com/doi/full/10.1108/02637470910979989 


\title{
Formulating strategic direction for a gated residential community
}

\author{
Richard W. Pouder \\ Department of Management, Appalachian State University, Boone, \\ North Carolina, USA, and \\ J. Dana Clark \\ Department of Hospitality and Tourism Management, \\ Appalachian State University, Boone, North Carolina, USA
}

\begin{abstract}
Purpose - Over the past two decades, a growing number of Americans have decided to live in gated residential communities. Academic research and case studies tend to focus on explaining this growth phenomenon from a range of perspectives, yet surprisingly little has been written about the preservation and growth of existing gated communities. In response to this gap in the literature, the purpose of this paper is to illustrate the use of strategic planning as a means of addressing issues that pertain to sustaining and growing gated residential communities.

Design/methodology/approach - This paper applies principles of strategic management to the process of planning for residential preservation and growth. The residential context is a golf-focused gated community located in the mountains of western North Carolina. It uses focus groups as a qualitative means of identifying important strategic issues. These issues serve as the basis for designing a survey for community residents. The survey results provide quantitative information that enables development of strategies targeted toward preservation and growth of the community.
\end{abstract}

Findings - Results from this paper suggest that traditional strategic planning techniques provide an effective method that common interest housing developments can use to help identify and respond to issues affecting their viability and growth.

Originality/value - This paper applies strategic planning techniques as a new area in the residential planning literature.

Keywords Communities, Strategic planning, Focus groups, Residential areas, United States of America Paper type Case study

\section{Introduction}

Over the past several decades, Americans have shown an increasing preference for living in privately governed residential enclaves, often referred to as common interest housing developments (CIDs). Evidence of this phenomenon can be seen in the rapid growth of CID construction. Much of this construction results in communities that have gates or walls separating the enclave from the surrounding area. In the mid-1990s, these so-called "gated communities" comprised nearly 20 percent of CID construction and housed an estimated 16 million Americans, about 6 percent of all households (Blakely and Snyder, 1997). By 1999, 12 percent of residents in metropolitan Phoenix lived in gated communities (Grant, 2005). Evidence that is more recent suggests that gated communities have emerged as the fastest growing form of CID. Developers estimate that 80 percent of new CID developments in the USA will involve gates (Grant, 2005). A trend toward growth in the construction of gated communities has also 
been documented in Australia (Eves, 2007), Canada (Grant, 2005; Townshend, 2006), and England (Blandy, 2006; Webster and LeGoix, 2005). Moreover, one sees gated communities as a real estate product with increasing global diffusion into countries such as Russia, Egypt, Turkey, and China, as well as throughout Latin America (Bellet, 2008).

Although scholars define gated communities in different ways, we cite Atkinson and Blandy (2005, p. 178) and define gated communities as:

[...] walled or fenced housing developments, to which public access is restricted, characterized by legal agreements which tie the residents to a common code of conduct and (usually) collective responsibility for management.

Because gated communities continue to grow as a preferred residential enclave, they have become an important topic in a widening pool of scholarly research. Much of this research relies on social, politico-legal, and economic underpinnings to explain why gated communities continue to diffuse globally. Some important reasons for the growth of gated communities include the following:

- postmodern societal needs for greater security and escapism (Bellet, 2008);

- response to, or fear of, crime among in wealthy communities (Manzi and Smith-Bowers, 2005);

- provision of packaged amenities that match residents' preferences and price range (Webster and LeGoix, 2005);

- endorsement by local governments who receive tax windfalls from not having to provide a range of services and facilities (McKenzie, 2005a);

- affordability by middle-income homebuyers because of rising real income and declining costs for monitoring and security (Manzi and Smith-Bowers, 2005); and

- a push by developers to maintain profits by seeking higher density in spite of rising land costs (McKenzie, 2005b).

In addition to discussing reasons for their growth, scholars have investigated some of the negative aspects of gated communities such as social and political fragmentation (Webster and LeGoix, 2005), which results in the creation of new barriers between the rich and the poor (Caldeira, 2000; LeGoix, 2005), and an increase in intracommunity social distance (Manzi and Smith-Bowers, 2005). Alternately, others have suggested positive attributes of gating such as the potential for building social cohesion and facilitating urban renewal (Manzi and Smith-Bowers, 2005) and efficient conservation of at-risk, congested, and depletable resources (Webster and LeGoix, 2005).

The importance of extant research notwithstanding, we set out to investigate the unexplored domain of sustaining and growing established gated communities. Given that the growth trend in gated communities "is not a passing fashion" (McKenzie, 2005b, p. 187) and that gated communities will increasingly populate the residential landscape, we ask: what must established gated communities consider to remain a viable economic and social entity? Because they are a type of organizational form designated as a CID, a gated community's mission is to defend the common interests of its residents (Bellet, 2008). Therefore, as in most established organizational contexts, gated communities must continue to fulfill the needs of their constituents; at the same time, they must also consider the vagaries of the world that lies outside of the enclave. 
The viability of gated communities thus requires their being aware of and responding to what transpires in their internal and external environments. For instance, communities may need to monitor their environments to consider such issues as the inevitable turnover of membership and tweaking their product to keep it viable for new owners. Not only must communities understand their current internal and external environments, but they also need to envision what environmental changes will likely develop over time (e.g. assessing the potential effect of adverse economic conditions). To address these concerns, we contend that gated communities, like many other contemporary organizations, should engage in strategic planning. Accordingly, this paper draws from theory and practice to create and apply a framework for strategic planning that gated communities and other CIDs can use to better sustain their viability and plan for growth.

\section{A case study of strategic planning in a gated community}

The gated community selected for this study (which we will call "Bushwood") lies in the Blue Ridge Mountains of North Carolina. Although some of Bushwood's residents are full-time residents, the majority are retirees who live there from May to October and spend the colder months in warmer climates. Bushwood typifies a gated community that provides all three of Blakely and Snyder's (1997) distinguishing features of American gated enclaves: prestige, lifestyle, and security. Arguably, residents of Bushwood could take advantage of this "multiple thematic foci" (Townshend, 2006) by using any combination of these features in their purchasing decision. The community offers a high level of security, including a 24-hour guarded entrance, camera-monitored surveillance, and fleet of security vehicles. Many residents also would have chosen Bushwood as a lifestyle community that focuses on its centrally located, high quality 18-hole golf course. Further, while homes are not in the price range of the most elite gated communities in the region, Bushwood is clearly a prestige community. The architectural style of residences and community buildings, landscaping, and geographic location combine to convey a sense of luxury and exclusivity. While the culture is friendly by community standards, there is a sense that the community is a place for privileged encounters. Personal and financial successes are the keys to open the door to acceptance in the community along with a sense of noblesse obliege.

\subsection{The situation at Bushwood}

During the years 2004-2006, Bushwood's Board of Directors (BOD) became increasingly aware of the community's need to respond to a host of issues that would likely affect its future success. The membership, however, had little experience in such issues, because Bushwood had outside ownership for its first 45 years as a gated community. Then, in 2003, the membership bought the community from its owner, thereby assuming full ownership and management roles. Recognizing the importance of identifying and taking action on issues affecting its future success, the BOD formed the long range planning committee (LRPC).

Over the next two years, many community members communicated to the LRPC their ideas and concerns about sustaining and growing Bushwood. Realizing the importance of this information from the community and other untapped sources of information, the LRPC concluded that Bushwood needed to formalize a process for identifying and responding to the community's needs. Several members of the LRPC 
recalled from their career experiences that strategic planning could help the community meet these needs. The committee also felt that an outside consultant could provide both expertise and objectivity in the strategic planning process. At that point, the LRPC decided to retain the consulting services of this study's authors.

Conducted as a formal, long-range planning process in most organizations, strategic planning envisions the organization's desired future outcomes and the actions needed to accomplish them. The outcome of the strategic planning process is a strategic plan, which states the organization's mission and vision, identifies and documents key organizational goals, develops strategies to achieve goals, and provides estimates of resource commitments and a period for implementing strategies. Strategic plans typically cover a period of three to five years, with many organizations conducting strategic planning as an ongoing process (Grant, 2008). The concepts used in strategic planning draw from the strategic management paradigm. Because of its importance in understanding the process of strategic planning, we briefly review this paradigm.

\subsection{Strategic planning and principles of strategic management}

Based in large measure on seminal works by Porter $(1980,1985))$, and more recent scholarly research in the resource-based view (Barney, 1991; Grant, 1991), strategic management focuses on organizations' systematic analysis of their external and internal environments as a means of formulating effective strategies. The external environment includes factors physically outside the boundaries of an organization. The internal environment includes the resources possessed by the organization and the activities in which they are used.

By systematically scanning external environments, organizations identify which factors create opportunities or pose threats. Similarly, by assessing their internal resources and activities, organizations identify their strengths and weaknesses. This form of organizational scanning and self-analysis, commonly known as strengths, weaknesses, opportunities, and threats (SWOT) analysis, guides an organization in determining what strategies it might develop in response to the opportunities and threats that it encounters in light of its ability to do so.

Table I lists elements comprising internal and external environments in the strategic management paradigm. Sustaining long-term viability and planning for growth in a gated community setting would take into account some of the opportunities and threats posed by general factors and competitive forces shown in Table I. For instance, strategic planning would likely consider buyer preferences and demographics for gated communities in the region. Because strategic management originated in a business context, external opportunities and threats include those posed by a company's competitive environment. These competitive forces, however, come into play in other types of organizations. For example, in an established gated community with growth aspirations, extant or new-gated communities represent potential threats. The availability of substitute forms of residential development such as non-gated CIDs could also threaten a gated community.

In their internal environment, organizations deploy pooled resources in activities with the intent of creating value (Grant, 1991; Porter, 1985). Activities in which the organization excels in creating value are called core competencies. For instance, a gated community that has a core competency in marketing through promoting or selling properties might draw from the pooled resources of skilled human capital and 


\begin{tabular}{ll}
\hline External & Internal \\
\hline General factors & Tangible resources \\
Economic conditions & Financial assets \\
Available technology & Organizational structure \\
Sociocultural preferences & Physical assets \\
Government influence & Technology \\
Demographic factors & Intangible resources \\
Natural environment & Human capital \\
Competitive forces & Image \\
Rivals & Culture \\
Buyers & Innovation \\
Suppliers & Activities \\
Substitute products & Management \\
Potential entrants & Operations \\
Complementary products & After-sales service \\
& Research and development \\
& Logistics \\
& Human resource management \\
& Purchasing \\
& Marketing \\
\end{tabular}

a capacity for innovation. The cornerstone of strategic management rests on the premise that organizations seek to build and sustain a competitive advantage by leveraging their strengths and overcoming their weaknesses. Intrinsic to competitive advantage is the organization's ability to develop core competencies characterized by a uniqueness that other organizations cannot easily replicate. In building uniqueness, organizations turn to their intangible resources, since they are most difficult for competitors to observe or understand (Barney, 1991; Grant, 1991). In a gated community, for example, a vaunted image and culture can act to set the community apart in ways that other gated communities may find hard to copy.

\subsection{The strategic planning process at Bushwood}

With community member approval, the LRPC assumed leadership in working with the consultants to design a process that ensured member input as the key source of information. After reviewing and discussing different approaches to strategic planning, the team selected an approach comprised of three major activities:

- Activity 1. Analysis of Bushwood's internal and external environments to understand its current situation and likely changes (SWOT analysis), and analysis of Bushwood's current mission and what it wants to be ten years hence.

- Activity 2. Documentation of what Bushwood wants to accomplish (prepare mission and vision statements, and formulate goals).

- Activity 3. Specify actions needed to meet goals (develop strategies with resource requirements and implementation timelines).

Figure 1 shows the sequence of steps followed in the strategic planning process. As a first step, the LRPC reviewed the ideas and concerns that members had earlier identified as crucial to the community's future. This enabled the planners to form 


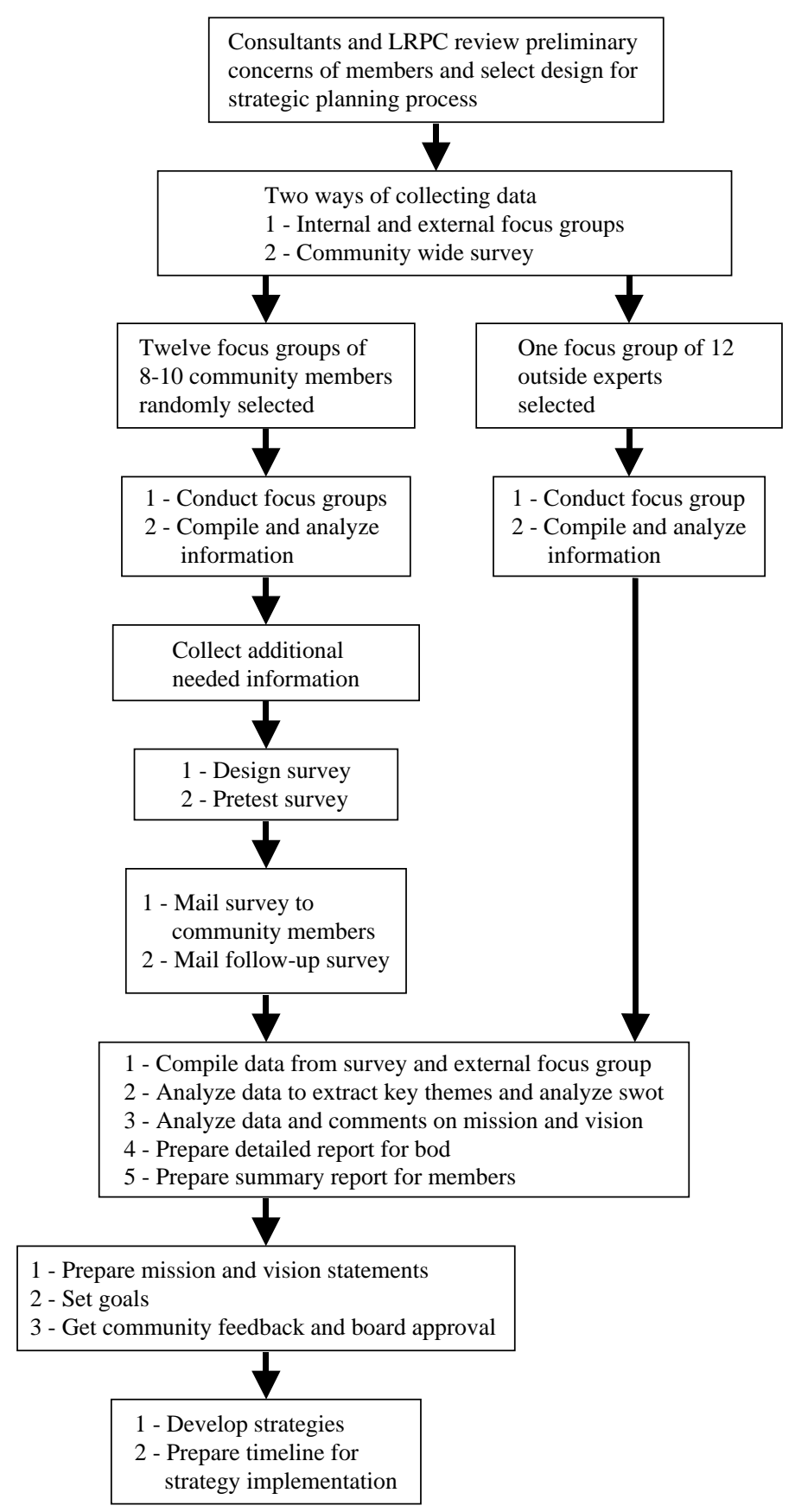

Figure 1. Sequence of steps in strategic planning process for a gated community 
an idea of key issues, which in turn helped in creating appropriate methods for obtaining information. The committee's decision was to conduct focus groups involving a portion of the community, followed by a questionnaire-based survey of the entire community as tandem methods for collecting information. The LRPC's purpose in conducting focus groups was to acquire valuable input for designing the questionnaire.

Formally defined, focus groups are randomly selected groups of interacting individuals having some common interest or characteristics, brought together by a moderator, who uses the group and its interactions as a way to gain information about a focused issue (Stewart and Shamdasani, 1990). By sharing and comparing their different points of view on the focused issue, focus group participants provide the moderator with rich information not just on what they think, but why they think the way they do.

To initiate the focus group phase, the LRPC randomly selected community members to participate in 12 focus group sessions. In line with suggested group size, focus groups consisted of eight to ten different members (Krueger and Casey, 2000). Each group met with the authors for about one hour and was asked to give their comments and opinions on questions that focused on:

- identifying factors important to Bushwood's survival and growth;

- characterizing the strengths, weaknesses, opportunities, and threats associated with these factors; and

- defining Bushwood's current mission and a vision of what it should aspire to over the next ten years.

In addition, the committee recognized the importance of using outside experts in key areas such as real estate, banking, trends in golf-focused gated communities, regional development plans, community infrastructure, and residential construction. To obtain this information, the LRPC assembled one focus group comprised of 12 external experts. These experts spent two days conducting an on-site inspection of Bushwood's facilities and then met as a group to provide their input.

For each of the 12 community member focus groups, one of the authors acted as the moderator, while the other author recorded responses to focused questions. Following recommended procedures, the authors analyzed and coded each focus group transcript shortly after the session, which they then compared to previously analyzed and coded transcripts (Glaser and Strauss, 1967; Krueger and Casey, 2000). The coding process entailed identifying themes that emerged from participants' comments about factors important to Bushwood's survival and growth. Consider, for example, the following comments on specific factors perceived as either strengths or weaknesses: "beautifully designed roadside flower beds," "well-maintained shrubbery," "too much money spent on landscaping," "less attention to golf course landscaping," and "charming alpine design of homes." The emergent themes in this case were landscaping and architecture. After coding and combining focus group results, the LRPC identified several unexpected information gaps and inconsistencies concerning real estate activities and residential purchasing decisions. These were addressed by collecting additional data from local real estate agents and recent buyers of homes in Bushwood.

The themes that emerged from the focus groups tended to cluster in 12 topical areas. For example, themes regarding landscaping and architectural design formed an area 
labeled "aesthetics." Each area defined a category for the questionnaire's choice sets as follows:

(1) Demographics. Age, income, geographic origin of community members.

(2) Marketing. How members had learned about Bushwood and what features of the community would be the most important to entice new members.

(3) Development. Extent of facility renovation, new facility construction, and new residential development.

(4) Amenities. Preferred dining, recreational, and social activities.

(5) Infrastructure. Extent of repairs on roads, water systems, sewers, and power lines.

(6) Real estate. Assessment of the Bushwood's real estate office.

(7) Membership. Numbers, types, and fees of/for members.

(8) Aesthetics. Architectural design standards and landscaping.

(9) Operations. Issues concerning governance, management, and staff.

(10) Financial. Annual membership assessments and reserve funds.

(11) Identity. Internal and external image of Bushwood.

(12) Vision. Bushwood's future directions and members.

The authors then designed an initial survey, which they pretested on five community members. After making several changes, the survey in final form was 17 typed pages and consisted of 49 multi-item questions. The last part of the survey was a written section in which respondents gave their thoughts on Bushwood's current mission and a long-term vision for the community, offered comments that expanded on themes in the survey, and discussed other concerns or opinions deemed important. An initial mailing to all 430 community residences, followed by a second mailing two weeks later to non-respondents, resulted in a response rate of approximately 70 percent.

Numerical data from the survey were then analyzed using SPSS statistical software. After typing respondents' written comments, the LRPC content analyzed over 100 pages of text to identify and categorize underlying themes. In addition to discussing Bushwood's mission and vision, much of the written section elaborated on themes contained in the main body of the survey, thereby helping the LRPC to better assess the relative importance and range of views on strategic issues.

The analyzed transcript from the external focus group was not included in the survey design, because much of the information provided by experts from outside the community differed substantially in content from information sought from community members. These experts focused most of their attention on how trends in the external environment were likely to affect Bushwood. The LRPC thus used the external focus group transcript as a direct source of information in conjunction with the results of the survey.

With survey data and input from the external focus group in hand, the LRPC set about its task of conducting Activity 1 . As a first step, the committee analyzed data in each area of the survey, focusing first on themes of sustaining and growing Bushwood. Themes chosen to be key elements in the strategic plan were those that respondents scored highest in importance. Additional insight on these themes came from the 
written response section of the survey. The LRPC then determined from the survey and external focus group information the strengths, weaknesses, opportunities, and threats associated with each chosen theme. In the second step of Activity 1, the committee analyzed sections of the survey that addressed Bushwood's mission and vision. Upon completing Activity 1, the LRPC provided detailed survey findings to the BOD and a summary report to all residents.

The LRPC began documenting its strategic plan in Activity 2. Using scored and written information related to mission and vision, the committee prepared Bushwood's mission and vision statements. The mission statement concisely defined Bushwood's current raison d'être, identified the basic services offered to residents, and described how it provided these services. The vision statement created a more idealized description of what Bushwood wanted to be after it had fully implemented its strategic plan. The purpose of these statements was twofold. First, they informed residents of a unified community identity, while envisioning a direction under its new member ownership. Second, they provided a broad context for defining the goals needed to sustain and grow the community. The LRPC documented these goals in written translations of what residents perceived most important as described above.

After making minor revisions to goals based on feedback received from the BOD and residents, the LRPC undertook Activity 3. In this last phase of strategic planning, the committee considered previously identified strengths, weaknesses, opportunities, and threats in the context of each goal in order to formulate strategies needed to achieve the goal. As a final step, the LRPC and BOD prepared for each strategy estimates of resource commitments and a period for implementation.

\subsection{An example from the strategic planning process}

Because a summary of Bushwood's strategic plan would add many pages of text, we briefly describe one example of a goal and the strategies planned to achieve it. The example goal, to increase community revenues, was chosen in response to "ensuring economic viability" emerging as a highly ranked theme in the survey. This goal and all others in the final strategic plan incorporated the mission and vision of the community, which focused on creating and preserving an ambience of casual elegance and authentic charm, providing a safe environment, enhancing community recreational and social activities, and maintaining financial independence.

The LRPC's SWOT analysis revealed other gated communities in the region and planned development of new gated communities as competitive threats. There were also existing and planned substitute forms of residential development in the region such as prestigious non-gated communities. These threats collectively gave homebuyers more choices and potentially increased their bargaining power. The trend in home sales for Bushwood and other regional gated communities showed an increase in the proportion of buyers who were professionals in their 40s and 50s, accompanied by a decrease in the proportion of buyers who were retirees. This rising demographic had greater disposable income, spent more time in the community, and preferred a wide range of community-provided activities such as golf, tennis, hiking, horseback riding, and swimming. At Bushwood, these new buyers had strong social ties to existing members based on the location of their full-time residences, primarily in three urban areas of North Carolina. 
Analysis of Bushwood's internal environment indicated weaknesses attributed to insufficient financial assets, moderate deterioration of infrastructure, and underutilization of the golf course. Alternately, the LRPC identified strengths in Bushwood's ownership of developable land with unique breathtaking vistas and the community's "chalet look." These were found to have high aesthetic appeal for the new demographic of buyer. Other strengths included Bushwood's culture, which enhanced its reputation as a "friendly" and "unpretentious" community. Much of Bushwood's historical success in attracting residents drew from these intangible resources. By leveraging its strengths, Bushwood developed a core competency in branding its uniqueness and niche appeal.

Drawing from its SWOT analysis, the LRPC concluded that Bushwood needed to increase revenues in the short run in order to maintain its long-term financial independence[1]. To increase currently available funds, the committee proposed a strategy that combined borrowing money, increasing membership dues, and opening the golf course to nonmembers for a fee to play during underutilized periods. Some of these funds would be used to make infrastructural improvements, thus preserving aesthetic quality. Other funds would be committed to a longer-term strategy of selecting developable sites with high aesthetic appeal for building new residential units. The LRPC's estimates indicated that profits from home sales and higher membership fees should generate sufficient revenues to ensure financial stability. The LRPC also developed a marketing strategy to promote the sale of new homes and homes for sale by existing owners. The strategy would target the younger professional demographic and use social networks and traditional external sources for marketing. The committee felt that the attractiveness of Bushwood's image and culture would sustain its competitive advantage over rival and substitute forms of residential communities.

\section{Conclusion}

With the recent rapid growth of gated communities expected to continue on a global scale, new questions surface about this increasingly preferred form of housing. An important question that housing experts must consider is how individual communities sustain themselves in the face of external opportunities and threats such as demographic trends, economic conditions, and competition with other communities for home buyers. In this paper, we proposed that gated communities could use strategic planning as a way of assessing their strengths and weaknesses so that they may create strategies that respond to opportunities and threats. We then outlined a method for strategic planning, which we applied in developing a strategic plan for a gated community in western North Carolina. As a practical matter, we contend that the strategic planning method described for Bushwood can serve as a useful model for strategic planning in other gated communities or CIDs.

There are several limitations of this study worth noting. For one, we do not know to what extent Bushwood actually implemented its strategic plan. Organizations sometimes prepare strategic plans but, for various reasons, implement only some of their planned strategies or change their planned strategies during the implementation phase. Perhaps, of greatest interest is knowing whether strategic planning actually results in achieving desired goals. Answers to these questions present opportunities for future research studies on gated communities. 


\section{Note}

1. Further support of the need to increase revenues came prior to strategic planning when the BOD had determined that Bushwood's current membership level was too low to maintain the community financially.

\section{References}

Atkinson, R. and Blandy, S. (2005), "Introduction: international perspectives on the new enclavism and the rise of gated communities", Housing Studies, Vol. 20 No. 2, pp. 176-86.

Barney, J.B. (1991), "Firm resources and sustained competitive advantage", Lournal of Management, Vol. 17 No. 2, pp. 99-120.

Bellet, C. (2008), "Privatisation, security, and spaces of simulation in the new city: gated communities in metropolitan area of New York", Working Paper No. 78, Department of Geography and Sociology, University of Lleida, Lleida.

Blakely, E.J. and Snyder, M.G. (1997), Fortress America: Gated Communities in the United States, Brookings Institution Press, Washington, DC.

Blandy, S. (2006), "Gated communities in England: historical perspectives and current developments", Geolournal, Vol. 66 Nos 1/2, pp. 15-26.

Caldeira, T. (2000), City of Walls, University of California Press, Berkeley, CA.

Eves, C. (2007), "Planned residential community developments: do they add value?", Property Management, Vol. 25 No. 2, pp. 164-79.

Glaser, B.G. and Strauss, A.L. (1967), The Discovery of Grounded Theory: Strategies for Qualitative Research, Aldine, Chicago, IL.

Grant, J. (2005), "Planning responses to gated communities in Canada", Housing Studies, Vol. 20 No. 2, pp. 273-85.

Grant, R.M. (1991), "The resource-based theory of competitive advantage: implications for strategy formulation”, California Management Review, Vol. 33 No. 3, pp. 114-35.

Grant, R.M. (2008), Contemporary Strategy Analysis, 6th ed., Blackwell, Malden, MA.

Krueger, R.A. and Casey, M.A. (2000), Focus Groups: A Practical Guide for Applied Research, 3rd ed., Sage, Los Angeles, CA.

LeGoix, R. (2005), "Gated communities: sprawl and social segregation in southern California", Housing Studies, Vol. 20 No. 2, pp. 323-43.

McKenzie, E. (2005a), "Constructing the Pomerium in Las Vegas: a case study of emerging trends in American gated communities", Housing Studies, Vol. 20 No. 2, pp. 187-203.

McKenzie, E. (2005b), "Planning through residential clubs: homeowners' associations", Economic Affairs, Vol. 25 No. 4, pp. 28-31.

Manzi, T. and Smith-Bowers, B. (2005), "Gated communities as club goods: segregation or social cohesion?”, Housing Studies, Vol. 20 No. 2, pp. 345-59.

Porter, M.E. (1980), Competitive Strategy: Techniques for Analyzing Industries and Competitors, The Free Press, New York, NY.

Porter, M.E. (1985), Competitive Advantage: Creating and Sustaining Superior Performance, The Free Press, New York, NY.

Stewart, D.W. and Shamdasani, P.N. (1990), Focus Groups: Theory and Practice, Applied Social Research Methods Series, Vol. 20, Sage, Newbury Park, CA. 
Townshend, I.J. (2006), "From public neighbourhoods to multi-tier private neighbourhoods: the evolving ecology of neighbourhood privatization in Calgary", Geolournal, Vol. 66 Nos 1/2, pp. 103-20.

Webster, C. and LeGoix, R. (2005), "Planning by commonhold”, Economic Affairs, Vol. 25 No. 4, pp. 19-23.

\begin{abstract}
About the authors
Richard W. Pouder is an Associate Professor in the Department of Management at Appalachian State University. His research and consulting focus on organizational change and application of the strategic management process to a range of planning contexts. Richard W. Pouder is the corresponding author and can be contacted at: pouderrw@appstate.edu

J. Dana Clark is an Associate Professor in the Department of Hospitality and Tourism Management at Appalachian State University. His research and consulting interests focus on various areas of organizational marketing and strategic planning for hospitality organizations.
\end{abstract}

